\title{
MORPHOMETRY OF THE EYES IN REGENERANT OF GENUS Dugesia (PLATYHELMINTHES, TURBELLARIA, DUGESIIDAE)
}

\author{
CAMPOS-VELHO, N. M. R. de, ${ }^{1}$ LOPES, K. A. R. ${ }^{1}$ and HAUSER, J. ${ }^{2}$ \\ ${ }^{1}$ Faculdade de Educação, Centro de Estudos da Natureza, Universidade do Vale do Paraíba, \\ Av. Shishima Hifumi, 2911, CEP 12244-000, São José dos Campos, SP, Brazil \\ ${ }^{2}$ Instituto de Pesquisas de Planárias, Universidade do Vale do Rio dos Sinos, \\ São Leopoldo, RS, Brazil \\ Correspondence to: Nádia Maria Rodrigues de Campos-Velho, Faculdade de Educação, Centro de Estudos da \\ Natureza, Universidade do Vale do Paraíba, Av. Shishima Hifumi, 2911, CEP 12244-000, \\ São José dos Campos, SP, Brazil, e-mail: nvelho@univap.br \\ Received November 28, 2002 - Accepted February 17, 2003 - Distributed February 29, 2004
}

(With 15 figures)

\begin{abstract}
The photodocumentation technique was used weekly to observe until the end of the regenerative process of eyes in three species of Dugesia. Morphometric data based on the measurement of 96 samples of the species: Dugesia tigrina, D. schubarti, and D. anderlani were analyzed A comparative analysis was made through graphic representation of statistical parameters of the following morphometric characters: the length of the transversal and longitudinal axes of the macula alba, pigment spot, and ocular opening. An interesting feature appeared in D. schubarti: the average of ocular opening during the regenerative process is bigger than in the original samples.
\end{abstract}

Key words: Dugesia, morphometry, macula alba, pigment spot, ocular opening.

\section{RESUMO}

\section{Morfometria de olhos em regenerantes do gênero Dugesia (Platyhelminthes, Turbellaria, Dugesiidae)}

A técnica de fotodocumentação foi utilizada para observar semanalmente os olhos de regenerantes de três espécies de Dugesia até o final do processo regenerativo. Os dados morfométricos analisados foram baseados na mensuração de 96 exemplares das espécies: Dugesia tigrina, D. schubarti e D. anderlani. Uma análise comparativa foi realizada por meio de representação gráfica de parâmetros estatísticos dos seguintes caracteres morfométricos: comprimento dos eixos transversal e longitudinal da mácula alba, cálice do pigmento e abertura ocular. $D$. schubarti apresenta um aspecto interessante: a média da abertura ocular na fase do processo regenerativo é maior do que nos exemplares originais.

Palavras-chave: Dugesia, morfometria, mácula alba, cálice de pigmento, abertura ocular.

\section{INTRODUCTION}

A study is presented of regenerant eyes in three planarian species: Dugesia tigrina (Girard, 1850), D. schubarti (Marcus, 1946), and D. anderlani (Kawakatsu et Hauser, 1983), all collected in Rio Grande do Sul State, Brazil. A systematic description of eye modification is done and regeneration development is compared.

The morphological changes in regenerant eyes are important, since newborn animals already present morphology identical to the of adult eyes. However, comprehensive research of the morphological changes, from birth to complete development, would 
require a study of embryos within the cocoon. Such an analysis would demand sophisticated microsurgical techniques, which are out of the scope of this work (Hauser, 1979; Campos-Velho, 1993).

An alternative way to study these changes is to follow the development of new eyes during head regeneration, when morphological development, including types and characters, can be investigated. A photodocumention technique was used to register observations every seven days. The pictures are of eye enlargement, with only the outlines indicated, and they will be mentioned in the section on material and method.

In general, most of the studies in the literature are based on histological data. This work presentes morphometric data, describing the different types and characters of the eyes in several developmental phases.

\section{MATERIAL AND METHODS}

\section{Location of study}

Dugesia tigrina planarians (Girard, 1850) were collected from a small lake on the grounds of Cristo Rei School, in São Leopoldo, Rio Grande do Sul State, on April 1989. The lake has a sandy bottom, where the planarians were found under rocks, together with small moluscs, fishes, and aquatic plants (Eichhornia sp.). In a small river of Barra Curta Alta, in Constantina, some specimens of $D$. schubarti (Marcus, 1942) were collected. They were found in a portion of the river, covered by vegetation, downstream from an approximately $2 \mathrm{~m}$ wide waterfall. The water temperature was about $17^{\circ} \mathrm{C}$. This specie is found exclusively in running water. Some samples were gotten from shallow water, which facilitated collection. The animals were under rocks fully or partially covered by water.

The D. anderlani planarians (Kawakatsu and Hauser, 1983) were selected from the Instituto de Pesquisas de Planárias (Planarian Research Institute), at the Universidade do Vale do Rio dos Sinos in São Leopoldo.

D. tigrina and D. schubarti were found in a sandy humic substratum (a mixture of sandy, mud, vegetative residue). Many rocks were also found. This location was chosen due to the access facilities and large number of animals. The planarians were sexually mature, averaging $1.3 \mathrm{~cm}$ and $2 \mathrm{~cm}$ in length for $D$. tigrina and D. schubarti, respectively, while $D$. anderlani planarians were nonsexual and ave- raged $1.8 \mathrm{~cm}$ in length. The measurements were done entirely through photographs.

\section{Anesthesia and cut}

The animals were anesthetized by putting them on ice covered with filter paper. This procedure is efficient and permits easy removal of the animals. Filter paper is used to prevent the animals adhering to the ice.

The head amputation procedure is as follows: using a stereomicroscope ZEISS SR and a small brush, the animals are placed on the ice and with a scalpel the head is amputated at level 1, i.e., just under the auricle. Sometimes a slight animal contraction at a light touch of the scalpel is observed, which prohibits cutting at the same place. However, that did not influence the regenerative process.

The head part is called part A; a the rest of the body is called part $\mathrm{B}$.

\section{Photodocumentation}

In order to analyze eye development, regeneration induction was necessary. The original head was photographed for comparison at the end of the regenerative process as well as to register the morphology and eye sizes; photodocumentation was used to observe eye development, after head amputation.

The photographic dossier was carried out with the help of a MINOX B camera with a flash coupled to a ZEISS SR stereo optical magnifying glass.

Part B was photographed, with its new head and two eyes growing from a regeneration cone. Part A, the original head, was not used in this work.

The new eye development was follow every two days by observation, and a weekly photographic register with 3.2 enlargement, was used to obtain eye measurements. The actual measurements were got with a measurement device photographed together with the specimen.

The regenerative process was photographed using 21 MINOX films: agfa ortho professional, iso 25 . The choice to work with 32 specimens was determined by the 32 exposures in each MINOX film, which is relatively expensive. The pictures were dipped in a developer of KODAK 76 and D-19 in a 9:1 proportion, at constant $21^{\circ} \mathrm{C}$ temperature.

The method of delineation based on eye limits was used. It was done with india ink and a $0.2 \mathrm{~mm}$ pen on an enlarged $52 \mathrm{~cm}$ photograph. Subsequently, a color removal process was 
perfomed in three steps: a) the photographs were put in a pot covered with water for 2 minutes; $b$ ) they were dried and put inside a plastic recipient for 2 minutes; c) the photographs were dipped quickly in the KODAK developer, and finally they were put in a vessel with flowing water, in order to remove excess developer. Next, the photographs were left to dry so as to be able to make the measurements. After developing the negatives, delineations were carried out with the MINOX reading device using a special paper.

\section{MEASURES AND STATISTICAL CHARACTERISTICS}

For measuring the morphometric characteristics, Heller's method (1985a) was used, which consists in the following measurements: a) length of longitudinal axis; $b$ ) width of longitudinal axis; c) length of transversal axis; d) width of transversal axis; e) ocular opening.

All measures were performed with the help of a caliper measuring in milimeters $(\mathrm{mm})$; all delineation were made on special paper. From each sample selected were measured:

- length of macula alba (axis A): measurement of longitudinal axis (LA);

- width of macula alba (axis B): measurement of transversal axis (TA);

- length of pigment spot (axis A): measurement of longitudinal axis (LA);

- width of pigment spot (axis B): measurement of transversal axis (TA);

- ocular opening: measurement of width between the external margin of the pigment spot between the two eyes.

All measurements were carried out using maximum length and width, and left and right corresponding to the point of view of the observer.

Plots were made from the averages, variation coefficients, and standard deviations for analysis of results. These statistical parameters are given, respectively, by:

$$
\bar{x}=\frac{1}{N} \sum_{i=1}^{N} x_{i} ; \quad s=\frac{1}{N} \sqrt{\sum_{i=1}^{N}\left(x_{i}-\bar{x}\right)^{2}} ; \quad d=\frac{s}{\bar{x}}
$$

where $N$ is the number of exemplars (sample size), $\bar{x}$ denotes the average, $s$ is the standard deviation, and $d$ is the variation coefficient. Although, the standard deviation and the variation coefficient indicate dispersion around the average, they permit analysis among different kinds of samples.

\section{RESULTS AND DISCUSSION}

A quantitative analysis for each species was perfomed, considering the measurements carried out for the following morphological characteristics of planarian eyes: macula alba, pigment spot, and ocular opening. The morphometric analysis is restricted to a general average, i.e., one related to both left and right eyes; an explanation is given below.

For all plots the following nomenclature is used:

moe $=$ average of the left eye;

$d p o e=$ standard deviation of the left eye;

cvoe $=$ variation coefficient of the left eye;

$\bmod =$ average of the right eye;

dpod = standard deviation of the right eye;

$c v o d=$ variation coefficient of the right eye;

mao $=$ average of the ocular opening;

dpao = standard deviation of ocular opening;

$c v a o=$ variation coefficient of the ocular opening.

\section{Dugesia tigrina}

Axis A of the macula alba (Fig. 1), in which the average presents similar characteristics for right and left eyes, with a little oscillation of standard deviation around $0.55 \mathrm{~mm}$, denoting a small spreading around the average, which also held for axis B (Fig. 2), with standard deviation of $0.24 \mathrm{~mm}$. The average for axis B suffers some oscillations, but after the sixth week, becomes constant up to the end of the regeneration process.

The evolution of the average of the pigment spot in the regeneration process is shown (Figs. 3 and 4) for axes A and B, respectively. In both axes a small standard deviation was observed, and an oscillation was verified in week 6 . For ocular opening (Fig. 5), the average decreases up to the third week, and subsequently increases up to the end of the process, with a final average similar to the initial one, and also showing a small standard deviation. 


\section{Dugesia schubarti}

The average evolution for macula alba axes $A$ and $B$ is shown in Figs. 6 and 7. The final average is significantly bigger than it was before amputation, and presents a small standard deviation. For the pigment spot, the data also reveals a small standard deviation, but poorer distribution in relation to the average for axis B than axis A (Figs. 8 and 9). Remarkable behavior is observed for the opening space average: by the fifth week, the biggest average is observed (Fig. 10). However, the average for the opening space at the end of the regeneration process is lower than it was for the original head.

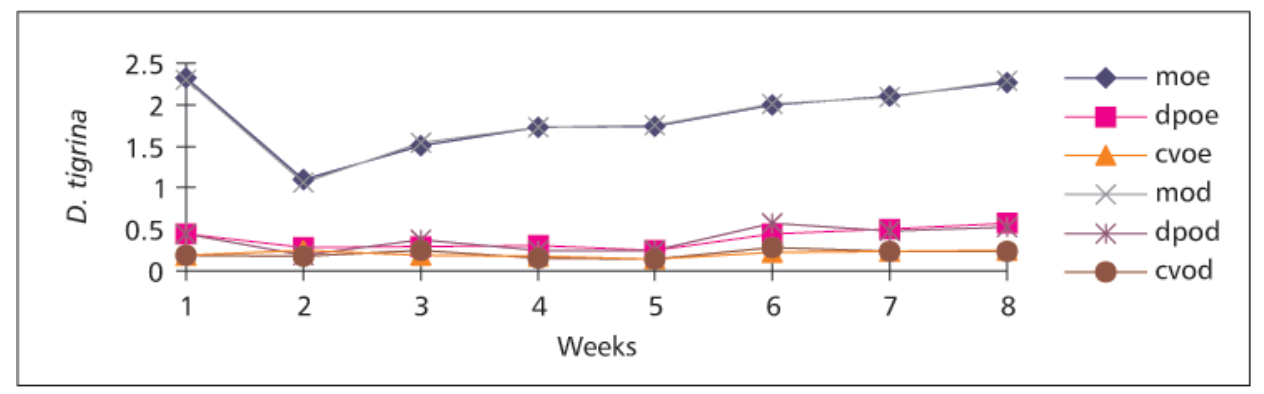

Fig. 1 - Statistical parameters - Dugesia tigrina - macula alba - Axis A.

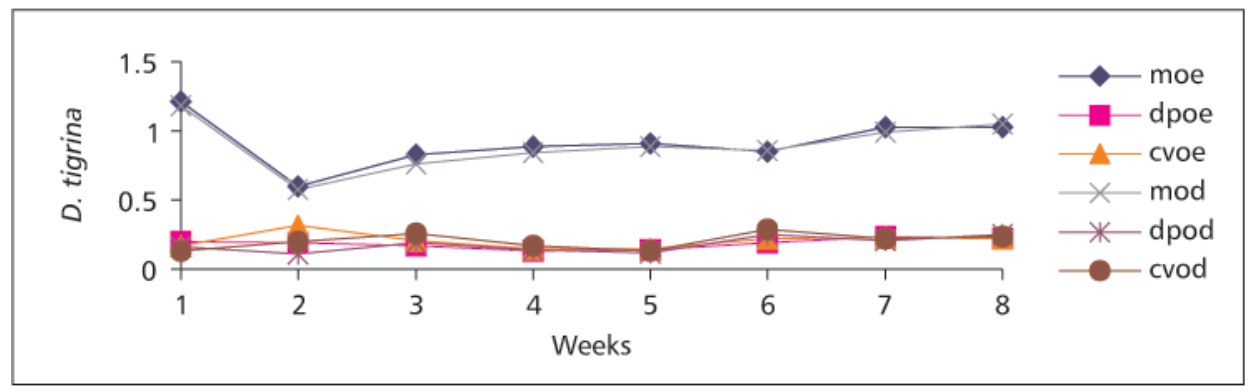

Fig. 2 - Statistical parameters - Dugesia tigrina - macula alba - Axis B.

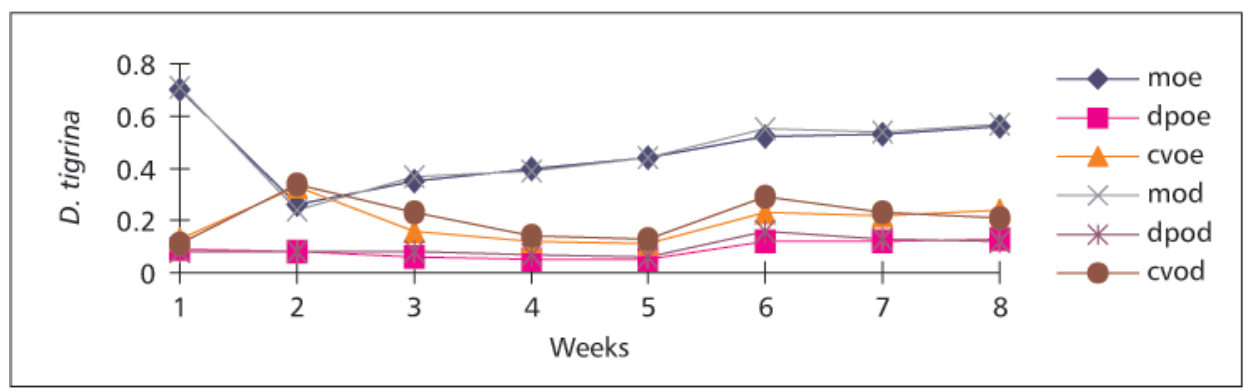

Fig. 3 - Statistical parameters - Dugesia tigrina - pigment spot - Axis A. 


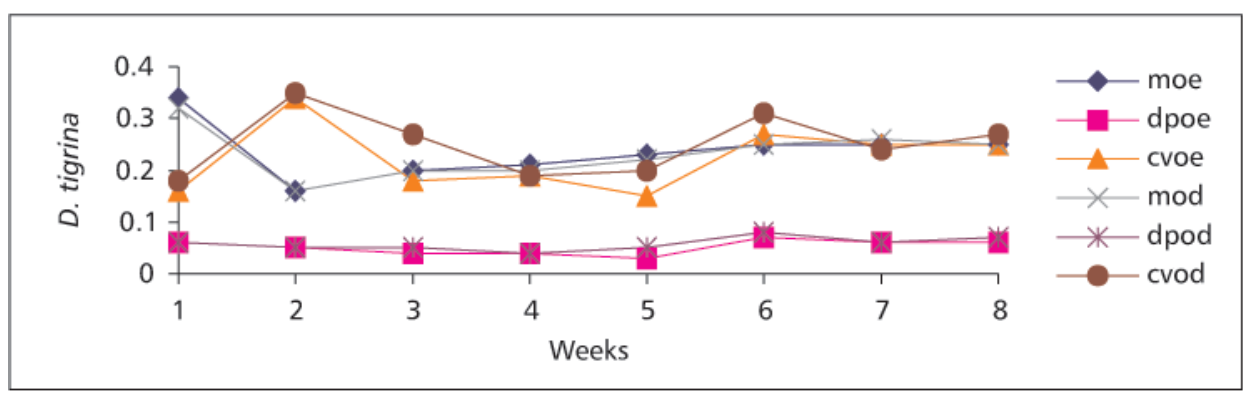

Fig. 4 - Statistical parameters -- Dugesia tigrina - pigment spot - Axis B.

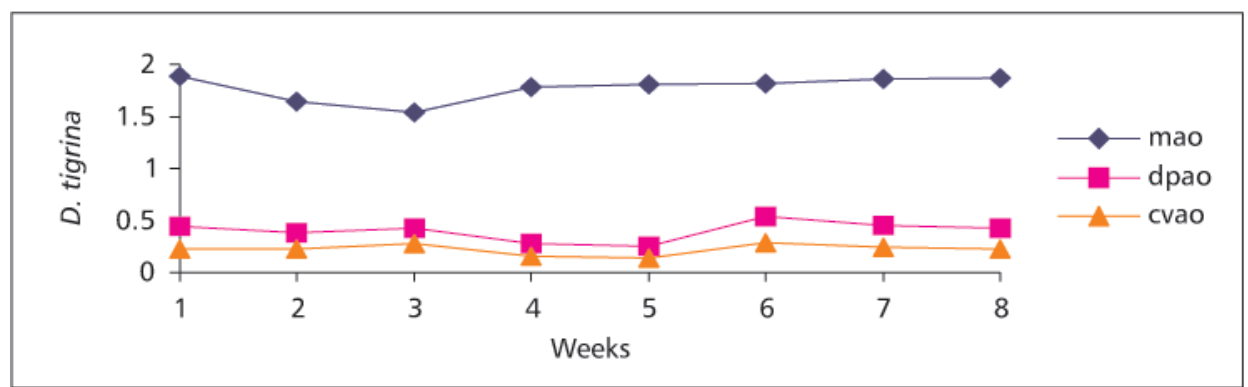

Fig. 5 - Statistical parameters - Dugesia tigrina - ocular opening.

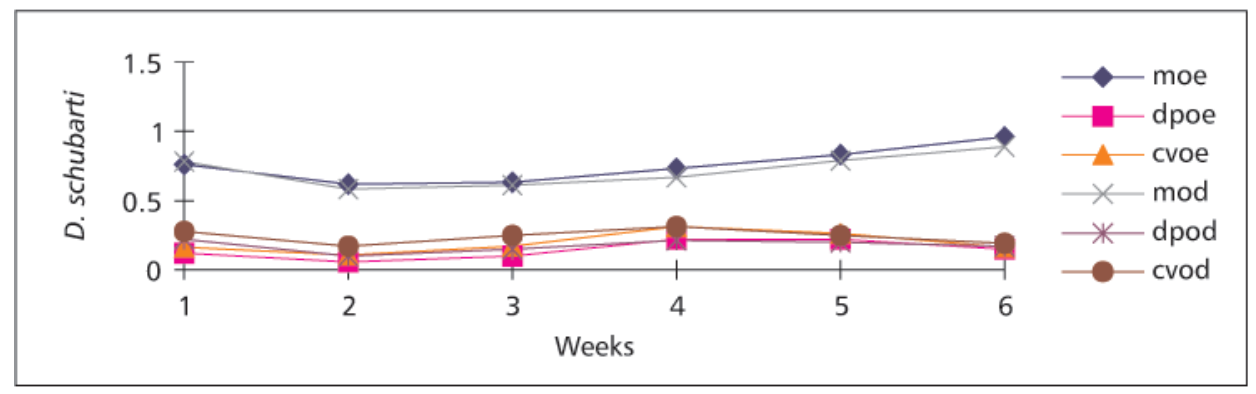

Fig. 6 - Statistical parameters - Dugesia schubarti - macula alba - Axis A.

\section{Dugesia anderlani}

The standard deviation for $D$. anderlani for macula alba and the pigment spot, for the right and left eyes and for both axes is very close. This means from the statistical point of view that the left and right eyes are morphometrically similar. For macula alba, axis A and axis B (Figs. 11 and
12) have small standard deviations, about $0.4 \mathrm{~mm}$ and $0.35 \mathrm{~mm}$ respectively. The pigment spot (Figs. 13 and 14) also presents a small standard deviation, but the growing ratio does not present oscillation of the macula alba, and the ocular opening (Fig. 15) presents a lower average during the fifth week. 


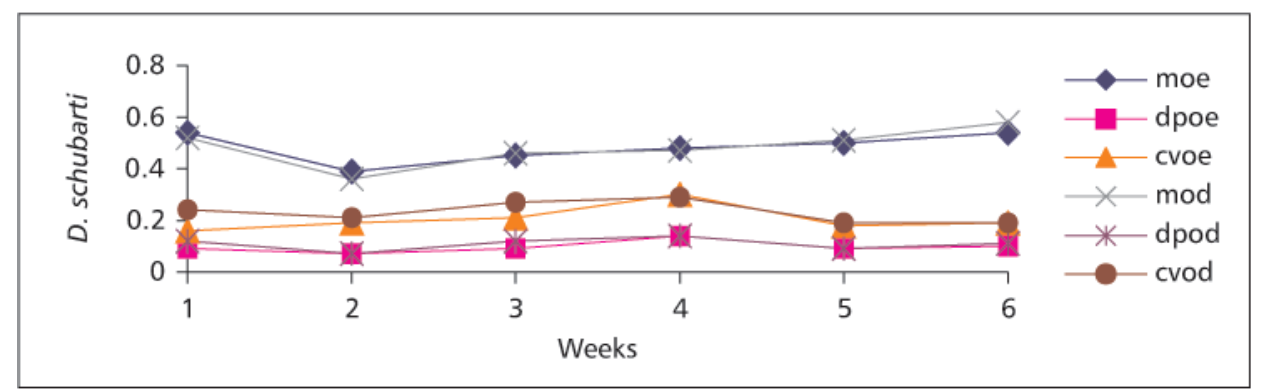

Fig. 7 - Statistical parameters - Dugesia schubarti - macula alba - Axis B.

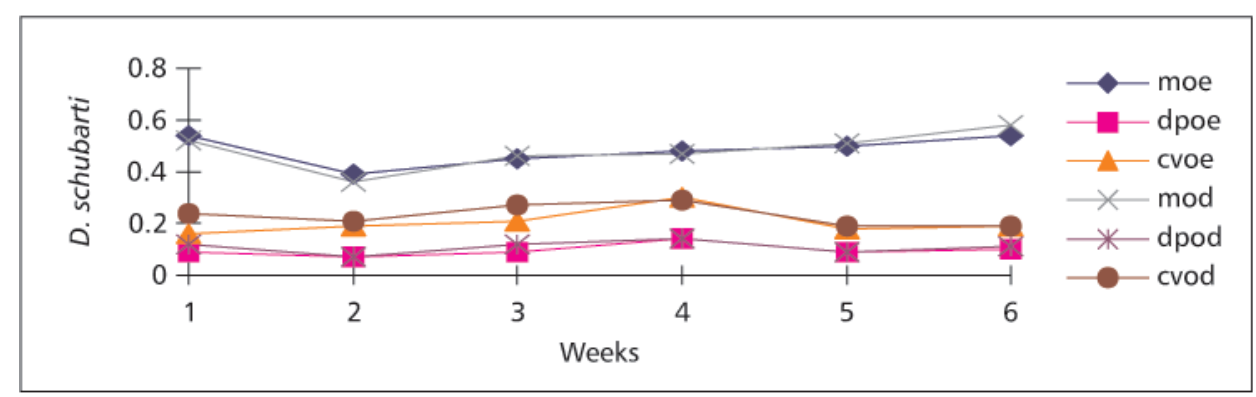

Fig. 8 - Statistical parameters - Dugesia schubarti - pigment spot - Axis A.

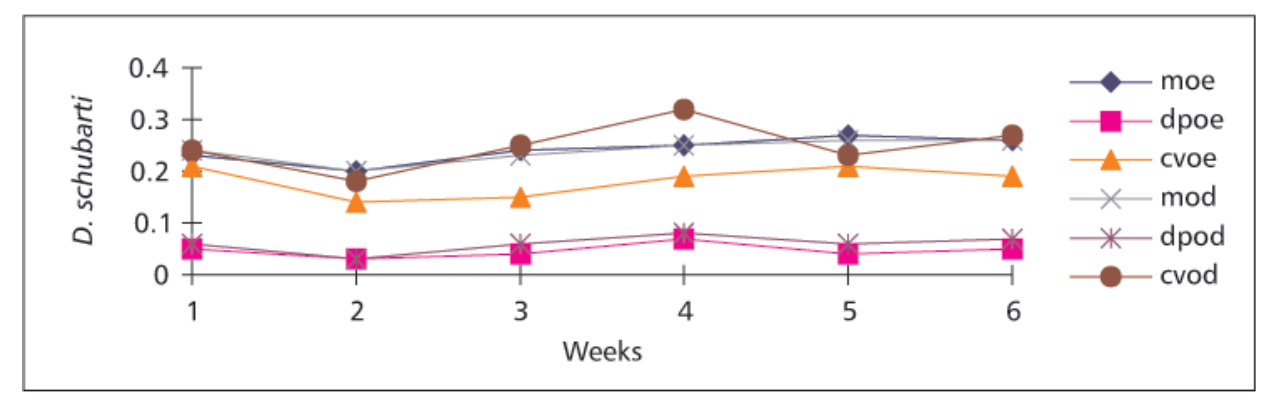

Fig. 9 - Statistical parameters - Dugesia schubarti - pigment spot - Axis B.

\section{Relation between morphometric parameters}

After individual analysis of each specie, it is useful to show a comparison among the parameters studied here. Axis A is approximately double the average of axis B for the macula alba in the three species. For axis B of D. tigrina, regenerant eyes are $13 \%$ smaller than those of the animal originally, while they are $14 \%$ bigger for $D$. shubarti and $D$. anderlani. 


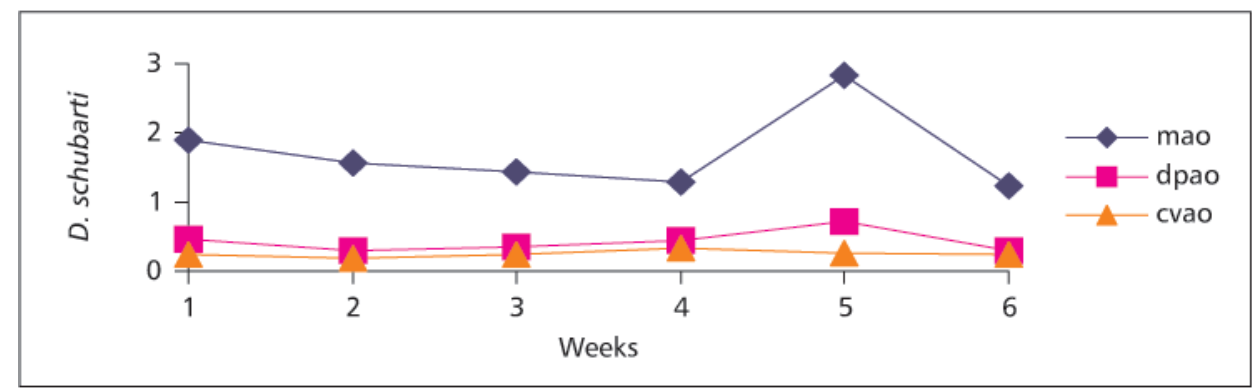

Fig. 10 - Statistical parameters - Dugesia schubarti - ocular opening.

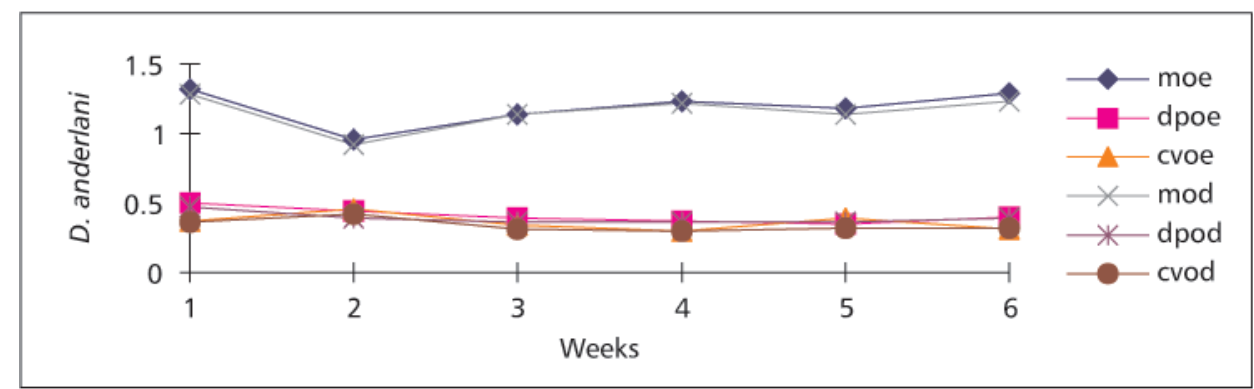

Fig. 11 - Statistical parameters - Dugesia anderlani - macula alba - Axis A.

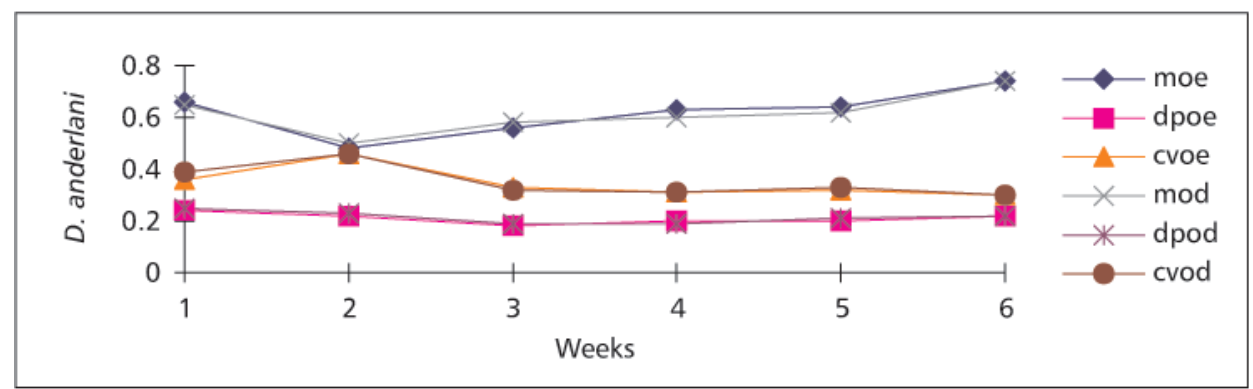

Fig. 12 - Statistical parameters - Dugesia anderlani - macula alba - Axis B.

The relation between axes A and B is constant for the pigment spot, i. e., the size for axis B is approximately half of axis A. Considering that the size for this character is about $30 \%$ of that of the macula alba for D. tigrina and D. schubarti, and about $45 \%$ for $D$. anderlani, only differences su- perior to $25 \%$ are considered significant, since the measurement tool is the same for all characters. Thus, only in axis A for the pigment spot of $D$. anderlani is there a morphometric change, by which the regenerant eyes are $46 \%$ smaller than those of the animals originally. 


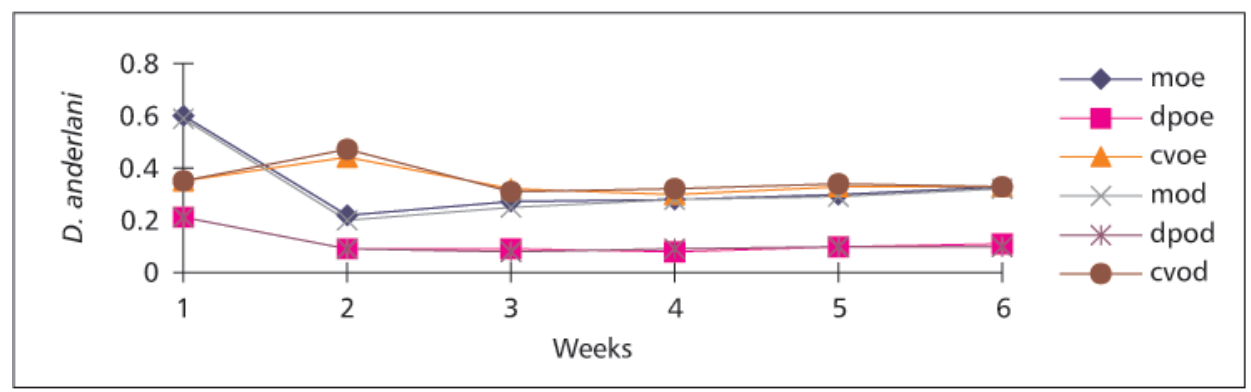

Fig. 13 - Statistical parameters - Dugesia anderlani - pigment spot - Axis A.

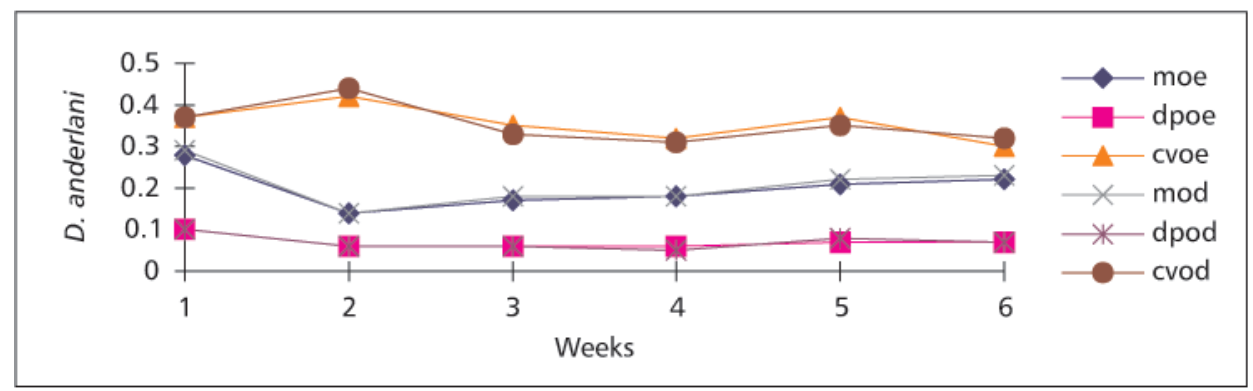

Fig. 14 - Statistical parameters - Dugesia anderlani - pigment spot - Axis B.

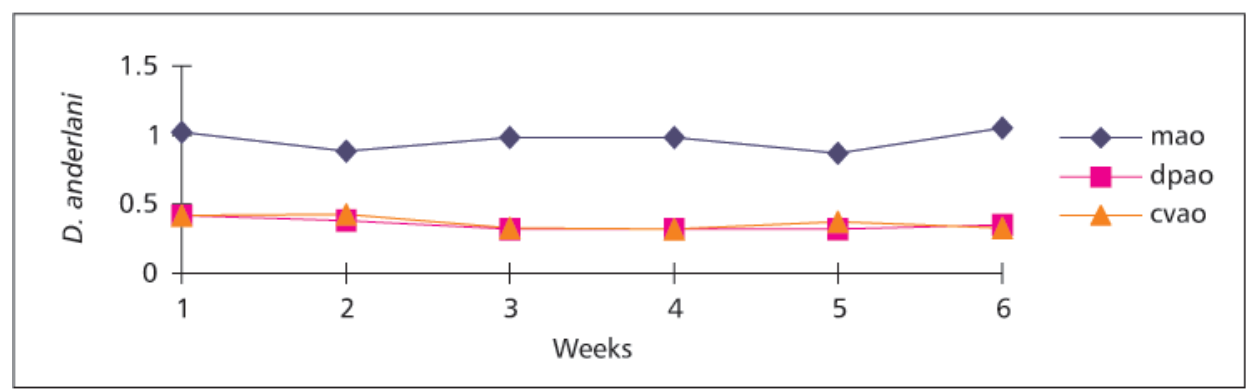

Fig. 15 - Statistical parameters - Dugesia anderlani - ocular opening.

For ocular opening, there is no change for $D$. tigrina and $D$. anderlani (differences are less than $3 \%$ ), but for D. schubarti the dimensions are $35 \%$ smaller for regenerant than for those of the original ones. The relative variation for morphometric characters between the animals originally and in the first step of regeneration. Using this statistic parameter, it is possible to determine which data are better distributed aound the average that present the variation coefficients for each specie and for each morphometric character.

$D$. tigrina and $D$. anderlani presented the biggest variation for pigment spot.

For a comparative study, the standard deviation is not an efficient parameter. For comparison among heterogeneous quantities the coefficient variation is used. Using this statistical parameter, it is possible to determine which data are better distributed around 
the average of variation coefficients for each specie and for each morphometric character.

\section{FINAL REMARKS}

After examining 32 individuals of Dugesia tigrina, D. schubarti, and D. anderlani, we observed that:

1. the longitudinal axis is approximately double the transversal axis, confirming statistically the enlarged character of the macula alba and the pigment spot for three species;

2. the characters do not differ between species (small standard deviation);

3. the longitudinal and transversal axes for the macula alba are always bigger, on average, for D. tigrina than for the two other species analyzed in the original animals and the regenerant ones. This can be used as an auxiliary criteria for specie identification;

4. the ocular opening of $D$. schubarti shows anomalous behaviour in a step in the regeneration process: its average in week 5 was larger in the original animal than in the final stage of the regeneration. This was not observed in the other two species;

5. the final sizes of the regenerant eyes were bigger for $D$. schubarti than original animals, except for the ocular opening. This was not verified for $D$. tigrina and $D$. anderlani.

The final morphometric dimensions of the regenerant eyes will be smaller than those of the original animals if the relative variation is superior to 0.5 , as that occurred which in D. tigrina for the macula alba, and D. tigrina and D. anderlani for the pigment spot.
The anomalous aspect indicated in item 4 for $D$. schubarti was also verified in the photodocumentation presented by Hauser (1979).

The average dimensions of morphometric features are bigger for $D$. tigrina than for $D$. anderlani, confirming the data obtained by Heller (1985a, b). However, the data in this work exceed those presented by Heller, who studied animals from São Franscisco de Paula (São Bernardo Lake) and Pelotas City. Both cities are in Rio Grande do Sul State, from which were collected $D$. tigrina and $D$. anderlani, respectively. In the present study, the $D$. tigrina and $D$. anderlani are from a lake in Cristo Rei School (São Leopoldo) and from a laboratory (Planarian Research Institute - IPP), University of Rio dos Sinos (UNISINOS). The differences in location can explain why the average observed in morphometric characters for this study are greater: the animals analyzed in São Leopoldo have an abundant source of food.

\section{REFERENCES}

CAMPOS-VELHO, N. M. R., 1993, Morfologia e morfometria: um estudo comparativo do desenvolvimento de olhos em regenerantes de três espécies do gênero Dugesia (Turbellaria; Tricladida; Paludicola; Dugesiidae. Tese de Mestrado, Pontifícia Universidade Católica do Rio Grande do Sul, Porto Alegre, RS, p. 138.

HAUSER, J., 1979, Modificações morfológicas nos olhos de Dugesia schubarti (Marcus, 1946) durante a formação da nova cabeça. Acta Biologica Leopoldensia, São Leopoldo, 1(2): 237-262.

HELLER, Z., 1985a, Study of the type and morphological characters of the eyes of the Dugesia tigrina (Girard, 1850). Acta Biologica Leopoldensia, São Leopoldo, 7(1): 77-90.

HELLER, Z., 1985b, Study of the external morphology of the eyes of the Dugesia anderlani (Kawakatsu et Hauser, 1983). Acta Biologica Leopoldensia, São Leopoldo, 7(1): 109-118. 